\title{
The yeast three-hybrid system as an experimental platform to identify proteins interacting with small signaling molecules in plant cells: potential and limitations
}

\author{
Stéphanie Cottier ${ }^{1 \dagger}$, Timon Mönig ${ }^{2}$, Zheming Wang ${ }^{2 \dagger}$, Jiří Svoboda $^{\dagger \dagger}$, Wilhelm Boland ${ }^{3}$, Markus Kaiser ${ }^{2}$ \\ and Erich Kombrink ${ }^{1 *}$
}

\author{
1 Department of Plant-Microbe Interactions, Max Planck Institute for Plant Breeding Research, Köln, Germany \\ ${ }_{2}^{2}$ Center for Medical Biotechnology, University of Duisburg-Essen, Essen, Germany \\ ${ }^{3}$ Department of Bioorganic Chemistry, Max Planck Institute for Chemical Ecology, Jena, Germany
}

\section{Edited by:}

Andreas P. M. Weber, University of Duesseldorf, Germany

\section{Reviewed by:}

Dominique Loqué, Lawrence Berkeley National Laboratory, USA Guillaume Pilot, Virginia Tech, USA Sona Pandey, Donald Danforth Plant Science Center, USA

\section{*Correspondence}

Erich Kombrink, Department of Plant-Microbe Interactions, Max Planck Institute for Plant Breeding Research, Carl-von-Linné-Weg 10, 50829 Köln, Germany.

e-mail: kombrink@mpipz.mpg.de

\section{${ }^{+}$Current Address:}

Stéphanie Cottier, Department of Biology, Division of Biochemistry, University of Fribourg, 1700 Fribourg, Switzerland;

Zheming Wang, Laboratory of Molecular and Chemical Biology of Neurodegeneration, Brain Mind Institute, École Polytechnique Fédéral de Lausanne, Al 2351 (Bâtiment Al)

Station 19, 1015 Lausanne,

Switzerland;

Jiř́ Svoboda, Zentiva Group, a.s., U Kabelovny 130, 10237 Praha 10, Czech Republic.
Chemical genetics is a powerful scientific strategy that utilizes small bioactive molecules as experimental tools to unravel biological processes. Bioactive compounds occurring in nature represent an enormous diversity of structures that can be used to dissect functions of biological systems. Once the bioactivity of a natural or synthetic compound has been critically evaluated the challenge remains to identify its molecular target and mode of action, which usually is a time-consuming and labor-intensive process. To facilitate this task, we decided to implement the yeast three-hybrid $(\mathrm{Y} 3 \mathrm{H})$ technology as a general experimental platform to scan the whole Arabidopsis proteome for targets of small signaling molecules. The $\mathrm{Y} 3 \mathrm{H}$ technology is based on the yeast two-hybrid system and allows direct cloning of proteins that interact in vivo with a synthetic hybrid ligand, which comprises the biologically active molecule of interest covalently linked to methotrexate (Mtx). In yeast nucleus the hybrid ligand connects two fusion proteins: the Mtx part binding to dihydrofolate reductase fused to a DNA-binding domain (encoded in the yeast strain), and the bioactive molecule part binding to its potential protein target fused to a DNA-activating domain (encoded on a cDNA expression vector). During cDNA library screening, the formation of this ternary, transcriptional activator complex leads to reporter gene activation in yeast cells, and thereby allows selection of the putative targets of small bioactive molecules of interest. Here we present the strategy and experimental details for construction and application of a $\mathrm{Y} 3 \mathrm{H}$ platform, including chemical synthesis of different hybrid ligands, construction of suitable cDNA libraries, the choice of yeast strains, and appropriate screening conditions. Based on the results obtained and the current literature we discuss the perspectives and limitations of the $\mathrm{Y} 3 \mathrm{H}$ approach for identifying targets of small bioactive molecules.

Keywords: yeast three-hybrid, hybrid ligand, small signaling molecules, protein target identification, plant defense, hormone signaling

\section{BACKGROUND: FUNCTIONAL IMPORTANCE OF SMALL MOLECULES}

Organic small molecules participate in many biological processes, such as metabolic pathways, signal transduction mechanisms, and developmental programs, in which they often play important, sometimes decisive roles. The binding of small molecules to their target proteins may be reversible or irreversible. In case of enzyme-substrate interactions, the small molecules are usually

\footnotetext{
Abbreviations: $\mathrm{ABA}$, abscisic acid; $\mathrm{AD}$, DNA-activating domain; $\mathrm{CA}$, cucurbic acid; CAMe, cucurbic acid methylester; Cpd8, compound 8; DBD, DNA-binding domain; Dex, dexamethasone; DHFR, dihydrofolate reductase; GR, glucocorticoid receptor; JA, jasmonic acid; JAMe, jasmonic acid methylester; Mtx, methotrexate; PEG, polyethylene glycol; $\mathrm{SA}$, salicylic acid; $\mathrm{Y} 3 \mathrm{H}$, yeast three-hybrid; $6 \mathrm{OH}-\mathrm{SA}$, 6-hydroxysalicylic acid (2,6-dihydroxybenzoic acid).
}

modified, whereas small signaling molecules acting as ligands remain unchanged but may initiate modification of their receptors, such as dimerization or phosphorylation (Cock et al., 2002; Lemmon and Schlessinger, 2010; Schulze et al., 2010; Jaillais et al., 2011; Li, 2011). When small molecules interfere with essential steps in biological processes, they may exert pharmaceutical functions, and many natural compounds are directly used as drugs or serve as lead structure for the development of synthetic molecules (Vuorela et al., 2004; Koehn and Carter, 2005; Molinari, 2009; Kinghorn et al., 2011). Signaling molecules may act at nodes of complementary signaling pathways in opposite manner, namely as activators and/or repressors, and hence their abundance and activity need to be tightly controlled. Such control mechanisms include synthesis and degradation of the small signaling molecules, as well as activation or inactivation by chemical modifications. 
The identification of proteins interacting with small signaling molecules is of fundamental importance for understanding the molecular mechanisms of signal perception and transduction.

In plants, the organic small molecules that largely dominate research activity are a group of well-established hormones, including auxin, cytokinin, gibberellin, abscisic acid (ABA), brassinosteroids, jasmonates, and salicylic acid (SA), which collectively, and each by its own influence numerous aspects of growth, development, and interaction with the environment (Grant and Jones, 2009; Pieterse et al., 2009; Depuydt and Hardtke, 2011). A long and arduous quest has only in recent years been successful by identifying the direct targets, i.e., the receptors, of most of the classical plant hormones mentioned above (Santner and Estelle, 2009; Lumba et al., 2010). Although thereby a tremendous leap in understanding the molecular mechanisms of plant hormone action has been made, in comparison to animal hormone perception our knowledge is still fragmentary and many details need to be unraveled; for example, how is selective activation of different physiological responses by a single hormone achieved, what is the functional significance of hormone modifications, how is crosstalk between hormone pathways mediated, or how is hormone action eventually turned off (Chow and McCourt, 2006; Santner and Estelle, 2009; Lumba et al., 2010)?

Phytotoxins are another class of small molecules that are critical for plant development and interaction with microbial pathogens (Speth et al., 2007; Strange, 2007; Möbius and Hertweck, 2009). They are low molecular weight substances produced by bacteria or fungi that impair plant performance and thereby influence the course of pathogen growth and disease/symptom development. To understand the mechanisms used by various pathogens to colonize their hosts, it is desirable to identify the cellular targets of phytotoxins and to unravel their modes of action. This knowledge may help to protect plants from fungal and bacterial colonization and to suppress disease development (Speth et al., 2007; Möbius and Hertweck, 2009). Similarly, beneficial plant-microbe associations as they occur in arbuscular mycorrhizal symbiosis and root nodule symbiosis rely on mutual exchange of chemical signals, which mediate host-specific recognition, and developmental alterations in host organs to accommodate the symbiont (Jones et al., 2007; Parniske, 2008; Badri et al., 2009; Kawaguchi and Minamisawa, 2010). In some instances the molecular mechanisms of this chemical dialog has been deciphered, e.g., the bacterial Nod factor and the related fungal Myc factor, both lipochitooligosaccharides, are recognized by plant LysM receptor kinases (Ercolin and Reinhardt, 2011; Maillet et al., 2011). However, for other chemical signals that are involved in symbiosis, such as flavonoids and strigolactones, the targets still remain to be discovered (Badri et al., 2009; Akiyama et al., 2010).

The diversity of small bioactive compounds has not only been exploited by nature, but also by man as agrochemicals and drugs to control weeds, pests, and diseases (Delaney et al., 2006; Walsh, 2007). The common principle of modern-day pesticide and drug development is to aim for highly selective compounds with nanomolar affinity (or better) that act on a single molecular target (Delaney et al., 2006; Casida, 2009). In addition to commercial applications, biologists are currently also performing chemical screens to identify bioactive small molecules that can be used to probe biological systems. This approach, referred to as chemical genetics, offers an alternative to classical genetics by substituting DNA mutations by systematic use of small molecules to elicit defined phenotypes in a biological system. Chemical genetic techniques have long been applied to animal systems in areas such as cancer research, cell death, and drug development (Stockwell, 2000, 2004; Mayer, 2003; Schreiber, 2003; Gangadhar and Stockwell, 2007), but more recently have also found application in plant biology (Blackwell and Zhao, 2003; Armstrong et al., 2004; Serrano et al., 2007, 2010; Walsh, 2007; Hicks and Raikhel, 2009; Knoth et al., 2009; Robert et al., 2009; Lin et al., 2010; McCourt and Desveaux, 2010; Tóth and van der Hoorn, 2010; Kim et al., 2011). Chemical genetics not only offers an alternative screening approach, it also has the potential to circumvent some of the inherent limitations of traditional forward genetics, such as lethality or redundancy of gene functions. In contrast to most mutations, a chemical enforced phenotype is conditional because bioactive molecules can be added at any time and dosages, and it is reversible because the chemical can in principle be removed. As previously pointed out by Smukste and Stockwell (2005), the success of a chemical genetic strategy relies on (1) a robust assay that reliably reports on a biological process, (2) the isolation of selective compounds that systematically perturb this process, and (3) the identification of the cellular targets regulating the process of interest. Many recent advances have facilitated chemical genetic screens, for instance synthesis of complex chemical libraries (Schreiber, 2000; Kaiser et al., 2008; Wilk et al., 2009), development of cell-based assays, and last but not least, automation of assay assembly (liquid handling) and phenotyping, which allowed high-throughput screening (Hicks and Raikhel, 2009). However, eventually, the identification of targets of bioactive molecules remains the biggest challenge of all.

\section{EXPERIMENTAL STRATEGIES TO IDENTIFY SMALL MOLECULE TARGETS}

The identification of small molecule targets that underlie the observed phenotypic response is not only important in the basic sciences for elucidating molecular mechanisms, but has also great practical implications, for example in structure-based drug design. In the plant field target identification of chemically reactive small molecules via a combination of affinity purification and proteomics is becoming more and more routine (Wang et al., 2008; Kaschani et al., 2009; Kolodziejek et al., 2011; Nickel et al., in press), whereas inert small molecules (non-covalently binding ligands) remain challenging. Traditionally, identification of targets was mainly achieved by applying biochemical in vitro methods in particular affinity chromatography or other separation technologies combined with photoaffinity cross-linking or radiolabeled ligand binding. These techniques have proven to be successful, but they also suffer from evident limitations, which are governed in parts by the intrinsic properties of the small molecule. For instance, high binding affinity of a ligand will facilitate target identification, whereas low binding affinity might result in the loss of target proteins, particularly when they are present in low abundance, as often the case for membrane-localized receptors. Thus, equilibrium kinetics dictates the amount of target in a protein extract that is required for its identification and 
isolation (Burdine and Kodadek, 2004; Terstappen et al., 2007). Furthermore, immobilization of a small molecule ligand on a solid support requires that an appropriate functional group or linker is introduced and that this modification does not disrupt or seriously impair the biological activity of the small molecule (Zheng et al., 2004). Although biochemical enrichment and detection methods have greatly improved in recent years, target purification and identification via affinity purification remains labor-intensive, time-consuming, and present-day versions relying on mass spectrometry and other profiling technologies are sophisticated and technically challenging (Lomenick et al., 2009; Rix and Superti-Furga, 2009).

Alternative technologies for target identification have been developed that circumvent the potential problems associated with low target protein abundance or low binding affinity. Genetic approaches are powerful because they can identify physiologically relevant targets, but they are limited to rapidly reproducing model organisms (e.g., bacteria, yeast, nematode, fruit fly, Arabidopsis) that allow screening of mutant populations for small moleculeresistant phenotypes (Zheng et al., 2004). The recently achieved deconvolutions of targets for several hormone-resistant Arabidopsis mutants are excellent examples for the success of this genetic strategy (Chow and McCourt, 2006; Chini et al., 2007; Thines et al., 2007; Murase et al., 2008; Shimada et al., 2008; Browse, 2009; Park et al., 2009; Santner and Estelle, 2009; Lumba et al., 2010), but they also document an enormous time gap between initial mutant isolation and target identification. Another set of methods has in common that identification of a small molecule target is combined with cloning of its cDNA (Terstappen et al., 2007). Such expression cloning technologies, including the yeast three-hybrid $(\mathrm{Y} 3 \mathrm{H})$ system, phage display and mRNA display, artificially increase the abundance of the target by expressing it as recombinant fusion protein, which may have properties that are different from the native original, in particular, when post-translational modifications are involved. Among these techniques, the $\mathrm{Y} 3 \mathrm{H}$ system is particularly appealing because it not only offers direct access to the genes encoding target proteins, but it also relies on small molecule-protein interactions in living cells rather than in vitro and it permits scanning of whole proteomes for targets (Kley, 2004; Terstappen et al., 2007). Importantly, this approach is not restricted to model organisms.

The $\mathrm{Y} 3 \mathrm{H}$ technology for studying protein-small molecule interactions was originally developed by Licitra and Liu (1996). It is an extension of the commonly used yeast two-hybrid system by introducing a third hybrid component, the small molecule linked to another ligand (Figure 1). Similarly, other $\mathrm{Y} 3 \mathrm{H}$ approaches have been developed to analyze tripartite interactions between proteins and (hybrid) RNAs (Jaeger et al., 2004; Vollmeister et al., 2009; Wurster and Maher, 2010). In plant systems this approach was initially used to identify and characterize different RNA-binding proteins (Maniataki et al., 2003; Campalans et al., 2004; Hwang et al., 2005), but more recent applications also served to monitor the assembly of trimeric protein complexes or to directly clone and identify bridging proteins, thereby allowing to screen for new signaling functions of proteins and peptides (Li et al., 2011; Nusinow et al., 2011; Rietz et al., 2011; Sheerin et al., 2011). With respect to protein-small molecule interactions, surprisingly, few reports document the successful application of the $\mathrm{Y} 3 \mathrm{H}$ system in search of novel targets. For example, the identification of cyclin-dependent protein kinases as well as other types of serine/threonine kinases was achieved by using various kinase inhibitors including the drug purvalanol B (Becker et al., 2004). Instead, the Y3H system has rather been used to confirm binding of pharmacologically active compounds, such as FK506, methotrexate (Mtx), or dexamethasone (Dex), to known targets (Licitra and Liu, 1996; Henthorn et al., 2002; Becker et al., 2004; Terstappen et al., 2007). To date, this variant of the $\mathrm{Y} 3 \mathrm{H}$ technology has not been applied to plant systems. In view of its apparent advantages, the implementation of a $\mathrm{Y} 3 \mathrm{H}$ platform for scanning whole plant proteomes for targets of small molecules can serve two main functions: (1) to establish complete catalogs of proteins interacting with small molecules that have signaling function in plant cells, such as hormones or toxins, and (2) to create a modular technology platform that allows and facilitates the identification of protein targets of bioactive small molecules that originate from high-throughput chemical screens, such as chemical activators or inhibitors.

\section{TOOL BOX FOR A FISHING TOUR: IMPLEMENTING THE Y3H PLATFORM}

To implement the $\mathrm{Y} 3 \mathrm{H}$ system as new fishing technique, we adapted already established fishing gear to our needs. As a variant of the yeast two-hybrid system, which is commonly used to identify protein-protein interactions (Fields and Song, 1989; Phizicky et al., 2003), the Y3H comprises three-hybrid components: (1) the hook, (2) the bait, and (3) the fish (Figure 1). The successful interaction of these three modules creates a competent transcriptional activator complex, which drives expression of a reporter gene. Cells expressing the reporter are selected and sequencing their plasmid DNA will reveal the identity of the small molecule target(s). A functional $\mathrm{Y} 3 \mathrm{H}$ platform requires strategies for designing and optimizing each of the involved hybrid components.

\section{DESIGNING THE HOOK}

The hook is a hybrid protein comprising two functional domains, the DNA-binding domain (DBD) and the ligand-binding domain. The Y3H systems reported previously rely on LexA or Gal4 as DBD to which various proteins have been fused to create the hook, including the glucocorticoid receptor (GR), FK506-binding protein 12 (FKBP12), and dihydrofolate reductase (DHFR). The common feature of these proteins is high-affinity binding of their ligands, dexamethasone (Dex), FK506, and Mtx, respectively (Lin et al., 2000; de Felipe et al., 2004). The previous successful application of these ligand-receptor pairs in various $\mathrm{Y} 3 \mathrm{H}$ systems also established that neither derivatization of the small molecule nor fusion of the receptor to the DBD impaired their binding capacities (Licitra and Liu, 1996; Lin et al., 2000; Henthorn et al., 2002; Baker et al., 2003; Becker et al., 2004; Schneider et al., 2008).

We opted for the $\mathrm{Y} 3 \mathrm{H}$ system expressing the hook vector encoding the LexA-DHFR fusion protein because DHFR binds Mtx with very high affinity (with $K_{\mathrm{D}}$ in the picomolar range (Cayley et al., 1981)) and it has been successfully used in Y3H screening (Becker et al., 2004). By this selection we could also take advantage of the yeast strain V874Y, which was engineered such that it contains two reporter genes, LEU2 and lacZ, integrated into its genome (Baker 


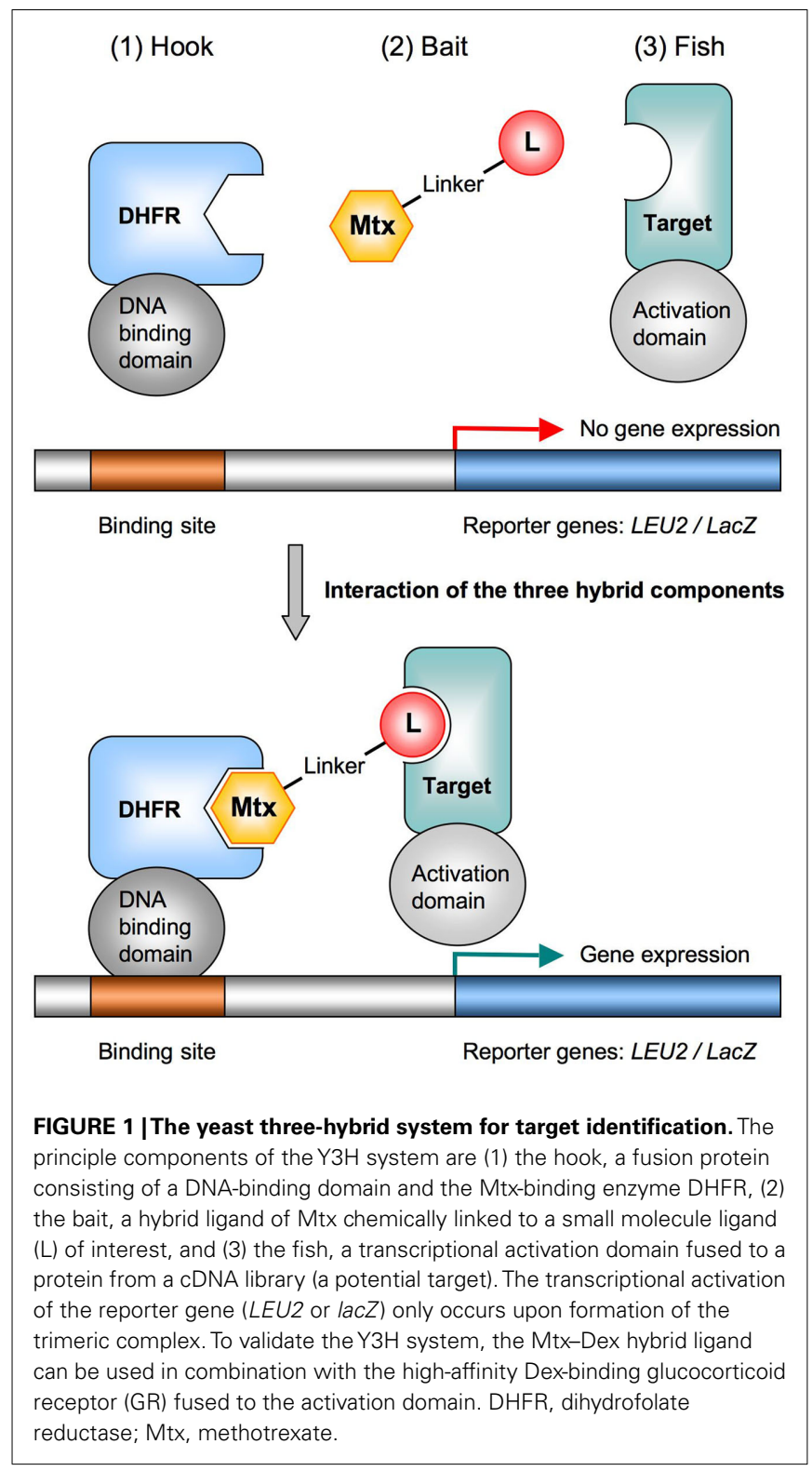

et al., 2003). Both reporters are placed under the control of LexA operators, whereas the hook, which is also integrated into the yeast genome, consists of fusion between the LexA DBD and DHFR under the control of the inducible GAL1 promoter. The phenotypic read-out of this integrated system was previously shown to be much more reliable than the plasmid-based system, resulting in significantly lower numbers of false negatives, i.e., white colonies in $\beta$-galactosidase assays (Baker et al., 2002, 2003).

\section{CUSTOMIZED BAITS: SYNTHESIS OF HYBRID LIGANDS}

Fishermen know, the right choice of bait will determine the success of a fishing trip. Here, the bait is a hybrid ligand in which an "anchor" moiety is covalently connected via a linker to a compound of interest (Figure 1). Each of these components can be varied, thus leaving head space for optimization and innovation (Licitra and Liu, 1996; Abida et al., 2002; Henthorn et al., 2002;
Baker et al., 2003; Becker et al., 2004; de Felipe et al., 2004; Dirnberger et al., 2006; Gallagher et al., 2007). However, for effective and affordable chemical synthesis of functional baits a few criteria should be considered. First, the "anchor" moiety should bind to the hook with high affinity and be amenable to facile chemical modification, thus making Mtx a prime choice. Second, the linker not only determines the distance (spacing) between the two ligands, it may also affect the solubility of the resulting hybrid ligand. Previous, systematic studies revealed that the linker between the two functional groups should have a minimum length of 5 carbon atoms to afford dimerization of the receptors, but a spacer length of 12 atoms would be most favorable, whereas the chemical nature of the linker had little impact on the biological read-out (Abida et al., 2002). However, a polyethylene glycol (PEG) linker will improve solubility of the hybrid ligand in comparison to an aliphatic linker. Third, coupling of the small molecule of interest to the linker should ideally not impair its biological activity, which should be verified by appropriate bioassays. Finally, chemical synthesis of baits should be designed such to provide a straightforward route of few and simple reaction steps operating with good yields.

We applied chemical solution phase synthesis to obtain a variety of baits. To this end, the investigated small molecule probes were connected via a polyethylene glycol (PEG) linker to the Mtx moiety. To couple the small molecule with the Mtx-PEG part, either free carboxylic acid residues [for ABA, JA, and compound 8 (Cpd8)] or hydroxyl moieties [for cucurbic acid (CA), cucurbic acid methylester (CAMe), and 2,6-dihydroxybenzoic acid] of the small molecule under investigation were used, resulting in either amide or ester linkages (Figure 2). In brief, the synthesis of the Mtx-PEG-amine intermediate relied on Nagy's protocol (Nagy et al., 1993) to generate the required Mtx intermediate. This compound was subsequently coupled with a PEG diamine residue, using standard peptide coupling conditions, to afford the key Mtx-PEG intermediate. For those small molecules that were linked to the Mtx-PEG moiety via their carboxylic acid moieties, a final standard peptide coupling between Mtx-PEG and the small molecule followed by cleavage of all protecting groups then afforded the desired baits. For those compounds that were linked via their hydroxyl groups, an additional step was required. The free hydroxyl group on the small molecule was first modified either with succinic anhydride (in case of CA and CAMe) or with an $\omega$-halo carboxylic acid (in case of 2,6-dihydroxy benzoic acid) to generate a carboxylic acid intermediate that was subsequently coupled to the Mtx-PEG residue under standard peptide coupling conditions. Cleavage of remaining protecting groups and purification by HPLC then delivered the hydroxyl-linked baits.

To test whether or not the Mtx-PEG-derivatized small signaling molecules had retained their biological activity, we applied bioassays that rely on activation of reporter gene expression in planta (Koornneef and Pieterse, 2008; Schneider et al., 2008). For example, Figure 3 shows that the hybrid ligands Mtx-JA and Mtx-CAMe, in contrast to JA, did not activate expression of the jasmonate-responsive LOX2p::GUS reporter gene (Figure 3A). By contrast, Mtx-ABA antagonized jasmonate-induced gene expression similar to $\mathrm{ABA}$, although at five times higher concentrations (Figure 3B). However, lacking bioactivity not necessarily 


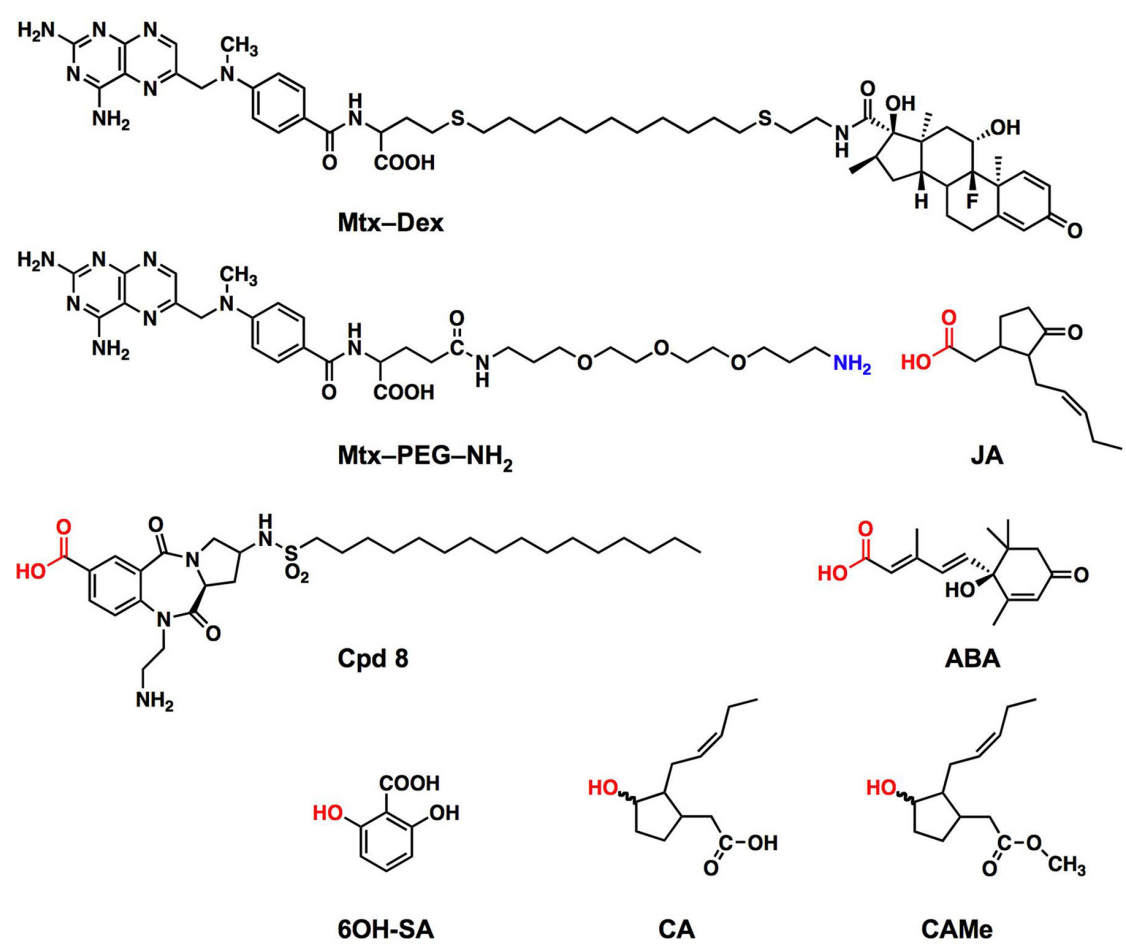

FIGURE 2 | Chemical structures of the hybrid ligands and compounds used in this study. The Mtx-Dex hybrid ligand as synthesized from the thiol derivatives of Mtx and Dex by Abida et al. (2002) contains a 10-methylene chain linker. All other baits were synthesized with polyethylene glycol diamine linker and the functional group of the small molecule used for coupling to the
Mtx- $(\mathrm{PEG})_{3}-\mathrm{NH}_{2}$ intermediate is highlighted in red, the hydroxy groups were converted to a succinyl ester $\mathrm{HOOC}-\mathrm{CH}_{2}-\mathrm{CH}_{2}-\mathrm{COO}-\mathrm{R}$ prior to coupling. JA, jasmonic acid; ABA, abscisic acid; CA, cucurbic acid; CAMe, cucurbic acid methylester; Cpd8, compound 8 (a palmitoylated benzodiazepinedione derivative); $6 \mathrm{OH}-\mathrm{SA}, 2$,6-dihydroxybenzoic acid. eliminates application of a bait from profiling experiments considering that it could bind to multiple targets, which may uncover new biological functions of a small molecule. This has recently been illustrated by a SNAP-tag-based $\mathrm{Y} 3 \mathrm{H}$ screen using a bait that was modified such to prevent binding of the drug erlotinib to its known target, epidermal growth factor receptor (EGFR) tyrosine kinase, which is highly expressed and occasionally mutated in various forms of cancer (Chidley et al., 2011). Indeed, the screen did not yield EGFR or any other kinase, but uncovered a new erlotinib target, oxysterol-binding protein-related protein 7 (ORP7).

\section{CREATING SCHOOLS OF FISH: SYNTHESIS OF cDNA LIBRARIES}

Fish is the target of a fishing tour and in the $\mathrm{Y} 3 \mathrm{H}$ system it is contained in the cDNA libraries. To date, mainly mammalian cDNA libraries have been used with the $\mathrm{Y} 3 \mathrm{H}$ technology (Licitra and Liu, 1996; Henthorn et al., 2002; Becker et al., 2004; Chidley et al., 2011). To increase the yield, it is common practice to screens various cDNA libraries with a bait. This allows isolation of multiple targets if these are differentially expressed in tissues or under certain conditions, and it reduces the odds of missing a target because it is not contained or underrepresented in a library. In general, working with multiple mammalian libraries is facilitated by the large collection that is commercially available (Becker et al., 2004; Chidley et al., 2011). Instead of screening whole libraries, it may also be useful to generate and screen custom cDNA arrays with specific baits, e.g., arrayed protein kinases with one or several kinase inhibitors (Becker et al., 2004).

For the synthesis of plant cDNA libraries, we employed the pDEST22 vector (Clone Miner ${ }^{\mathrm{TM}}$ cDNA Library Construction Kit, Invitrogen, Life Technologies, Darmstadt, Germany). This vector is appropriated for the $\mathrm{Y} 3 \mathrm{H}$ system because (1) it generates fusion proteins of the cloned CDNA with the GAL4 activation domain, (2) it contains TRP1 as selection marker for transformation into the employed yeast strain V874Y, which is auxotrophic for tryptophan, and (3) it relies on the Gateway ${ }^{\circledR}$ recombination cloning technology, which adds flexibility to the systems because any plant cDNA library that was cloned into a Gateway ${ }^{\circledR}$ pDONR $^{\mathrm{TM}}$ vector can easily be shuttled into pDEST22 (Schneider et al., 2008). In addition, the Gateway ${ }^{\circledR}$-based system also allows transferring the cDNA libraries to alternative $\mathrm{Y} 3 \mathrm{H}$ platforms such as the split-ubiquitin-based system (Johnsson and Varshavsky, 1994; Dirnberger et al., 2006) or the Sos recruitment system (Aronheim et al., 1997; Aronheim, 2001; see below). Once a fish is hooked, i.e., a target protein has bound to its small molecule ligand contained in the bait, the assembled transcriptional activator complex initiates expression of the reporter gene (Figure 1). We note that the quality of cDNA libraries is of critical important for the success of any screen. Therefore, we made sure that our libraries represents diverse and full-length cDNAs (average insert size $1120 \mathrm{bp}$ ) and appropriate marker/candidate genes are contained, e.g., AOS, OPR3, JAR1, COI1, and LOX2 for JA signaling. 


\section{MÉNAGE À TROIS: SCREENING WITH THE Y3H SYSTEM TESTING THE FUNCTIONALITY OF THE SYSTEM}

Before starting extensive screening programs with the $\mathrm{Y} 3 \mathrm{H}$ system, it is appropriate and advisable to test the proper cooperation of its three key components because the synthesized baits are relatively large molecules $\left(M_{\mathrm{r}} \geq 1.000\right)$ and their uptake by the yeast cells cannot be taken for granted. In addition, hybrid

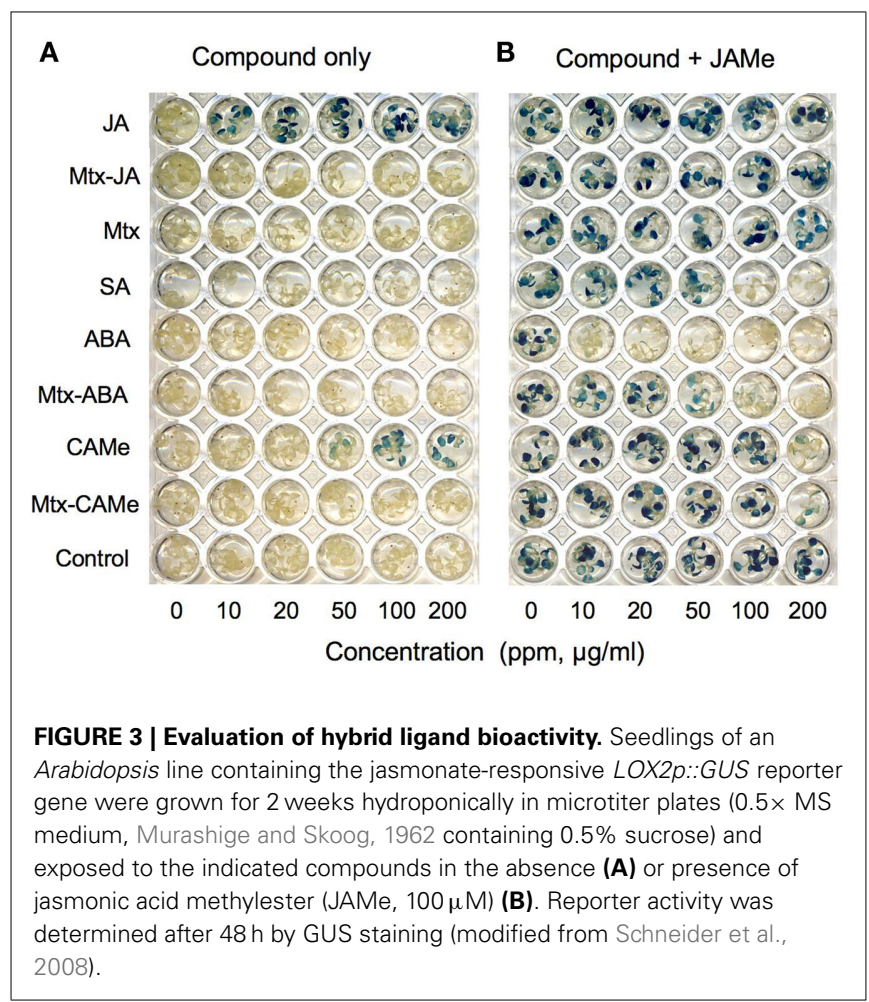

ligands could be toxic and impair growth. The yeast Saccharomyces cerevisiae is only weakly permeable for drugs and has efficient transporters catalyzing extrusion of structurally and functionally unrelated compounds out of the cells, thus mediating a phenotype known as multidrug resistance (Moye-Rowley, 2003; Gbelska et al., 2006; Gulshan and Moye-Rowley, 2007). To test for functionality, we took advantage of the well-characterized interaction of DBD-DHFR, Mtx-Dex, and AD-GR in the Y3H system (Lin et al., 2000). First, we confirmed that cells of strain V874Y transformed with GR inserted in pDEST22 grow on selective medium only in the presence of Mtx-Dex (Figure 4A). Secondly, we supplemented this complete assay with increasing concentrations of newly synthesized hybrid ligands, e.g., Mtx-CAMe, to compete with Mtx-Dex binding. Decrease in reporter gene activity, i.e., reduced yeast growth on selective medium, was obtained with all baits investigated, strongly suggesting that the baits were properly translocated into the yeast nucleus where they competed with Mtx-Dex for binding to DBD-DHFR (Figure 4A). Finally, we excluded the possibility that baits are toxic to yeast; no growth restriction was observed on media containing baits at 100-fold higher concentrations than used for screening.

\section{YIELDS OF A FISHING EXPEDITION}

The initial aim for establishing the $\mathrm{Y} 3 \mathrm{H}$ platform focused on small signaling molecules known to mediate plant defense responses including jasmonates, $\mathrm{SA}$ and $\mathrm{ABA}$, because these hormones act synergistically or antagonistically in regulatory networks, but the underlying molecular mechanisms of this signaling cross-talk are not yet understood (Mauch-Mani and Mauch, 2005; Koornneef and Pieterse, 2008; Spoel and Dong, 2008; Pieterse et al., 2009). Correspondingly, we synthesized five baits: they consisted of Mtx bound via a PEG spacer to jasmonic acid (Mtx-JA), cucurbic acid (Mtx-CA), cucurbic acid methylester (Mtx-CAMe), abscisic

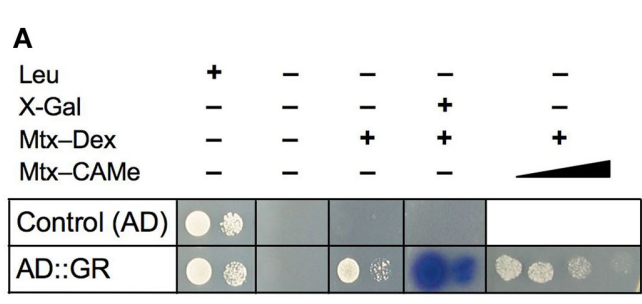

FIGURE 4 | Monitoring small molecule-protein interactions using the yeast three-hybrid system. (A) Validation of the Mtx-based system: expression of the hook gene (DBD::DHFR) and the empty fish vector as control $(A D)$ conferred cell growth on galactose-containing synthetic complete (SC - His - Ura -Trp +Leu) medium but not on SC - His -Ura -Trp - Leu medium. On selective medium (-Leu) only yeast expressing the Dex-binding fusion protein, $A D:: G R$, grew in the presences of Mtx-Dex, and when X-Gal was simultaneously added, also the expression of the second reporter gene (lacZ) was detectable (galactosidase activity). Yeast suspensions were plated at two different densities, $4 \times 10^{4}$ cells/dot (left) and $4 \times 10^{2}$ cells/dot (right). Competition assays indicated that all hybrid ligand were readily taken up by yeast cells: Addition of increasing concentrations of other baits to Mtx-Dex-containing medium, here shown for Mtx-CAMe, resulted in suppression of reporter gene expression and cell growth,

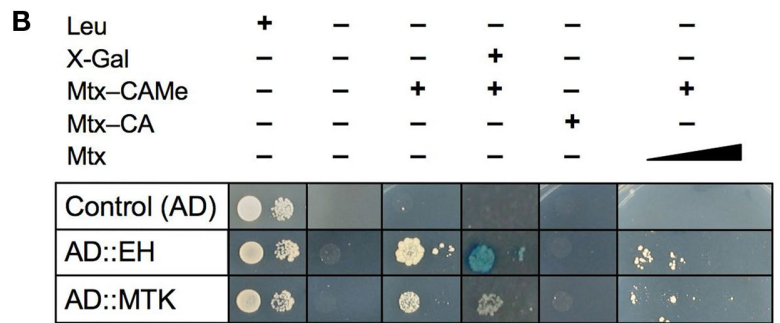

indicating that formation of the trimeric transcriptional activation complex was prevented. (B) Verification of new candidate targets identified from $\mathrm{Y} 3 \mathrm{H}$ screens with the hybrid ligand Mtx-CAMe. Plasmid DNA (fish vector) of two candidates identified in the initial screen was isolated and transfected into new yeast cells harboring the hook, DBD::DHFR. All yeast cells grew on + Leu but not on - Leu medium, including cells containing only the empty fish vector (control AD). By contrast, when hook vector $(D B D:: D H F R)$ and the fish vector harboring either of two CAMe-binding proteins ( $A D:: E H$ or $A D:: M T K)$ were spotted on different selective media (-Leu), reporter gene activation (growth and galactosidase activity) was observed in presence of the specific bait, Mtx-CAMe, but not in the presence of alternative baits such as Mtx-CA, indicating that the interactions are highly selective. Addition of increasing concentrations of Mtx out-competed Mtx-CAMe-dependent growth. EH, epoxide hydrolase; MTK, 5-methylthioribose kinase; for other abbreviations see text. 
acid (Mtx-ABA), and the SA derivative 2,6-dihydroxybenzoic acid (Mtx-SA; Figure 2). Note that both Mtx-JA and Mtx-CA are jasmonate-derived baits, but the Mtx-PEG unit is attached to different functional groups and therefore the "jasmonate" residue is presented in opposite orientation. This variation was designed to minimize the risk of missing targets because an essential functional group for binding is masked in the hybrid ligand. In addition, we also used an unrelated hybrid ligand for screening that was designed as specific inhibitor of mammalian acyl protein thioesterase 1 (APT1), which catalyzes the depalmitoylation of the Ras protein (Deck et al., 2005). This inhibitor, compound $8(\mathrm{Cpd} 8)$, is a palmitoylated benzodiazepinedione derivative and a structural mimic of the C-terminus of processed H-Ras (Deck et al., 2005).

We extensively screened several Arabidopsis thaliana cDNA libraries that were synthesized from inflorescence, wounded or pathogen-infected leaves (Schneider et al., 2008). Jasmonates are known to play important roles in these tissues and processes and we made sure that the selected cDNA libraries contained potential targets (Stintzi and Browse, 2000; Li et al., 2004; Wasternack, 2007; Browse, 2009; Koo and Howe, 2009; Wasternack and Kombrink, 2010). Transformation of yeast cells with the library and the subsequent screening followed standard protocols (Gietz and Woods, 2002; Becker et al., 2004). In brief, primary yeast transformants (at least $10^{6}$ per library) were plated on selective medium (Synthetic Complete medium + Gal - His - Ura - Trp -Leu) supplemented with baits $(10 \mu \mathrm{M})$ and grown colonies directly re-streaked on selective media plus and minus the respective bait. All clones surviving this second selection also survived selection after retransformation of plasmids into new yeast cells and thus were considered true candidates. The hybrid ligands Mtx-JA, Mtx-CA, and Mtx-ABA did not yield any candidate binding proteins from several million clones analyzed. By contrast, hybrid ligands containing CAMe, SA, and Cpd8 uncovered specific candidate targets. A putative epoxide hydrolase $(\mathrm{EH})$ and 5-methylthioribose kinase (MTK) were found to interact with Mtx-CAMe, serine/threonine protein phosphatase 2C (PP2C6) with Mtx-SA, and several members of the squamosa promoterbinding protein (SBP) transcription factor family, SPL3, SPL4, and SPL13 with Mtx-Cpd8 (Table 1). We note that proteins were considered candidate targets only after stringent validation comprising secondary screens and several other control treatments: (1) The fish vector was isolated from cells identified in the first selection round and re-transformed into new yeast cells, which were again subjected to selective medium. This eliminates the possibility that initial yeast growth is due to unwanted background mutations in the yeast genome. (2) Growth of yeast cells expressing a particular candidate was strictly dependent on the presence of the corresponding bait in selective medium (-Leu), whereas other baits did not support growth. (3) We checked that the activation of the LEU2 reporter gene was strictly dependent on the formation of the ternary complex between hook, bait, and fish. As predicted, increasing concentrations of Mtx out-competed the interactions and suppressed yeast growth on selective medium (Figure 4B). (4) In addition to $L E U 2$, the yeast cells harbor lacZ as second reporter gene. However, its activity was detectable only with some candidates (e.g., EH) and not with others (e.g., MTK), which presumably reflects the strength of the protein-ligand interaction. Finally, as evident from Table 1, the number of clones isolated for individual candidate targets varied considerably, ranging from 1 to 37. Again, this can be considered as indicator of interaction strength and/or abundance of a particular candidate target in the corresponding sample (cDNA library).

The number of candidate targets we identified in our screens is too low to draw general conclusions and yet, intriguingly, we uncovered three enzymes interacting with JA or SA derivatives and three members of a transcription factor family interacting with Cpd8. For the enzymes it can be speculated that they either catalyze conversion of the corresponding compound (or a related derivative) or that their enzymatic activity is regulated by ligand binding. Enhanced expression and activity of EH have been associated with pathogen defense and protection from oxidative damage in several plant species, although a bona fide substrate remained elusive (Guo et al., 1998; Gomi et al., 2003; Wijekoon et al., 2008,

Table 1 | Candidate target proteins identified using the yeast-based screening platform for profiling of small molecule interactions.

\begin{tabular}{|c|c|c|c|c|c|c|}
\hline Protein target $^{a}$ & Function & Locus ID & Bait & cDNA Library & Activation of $l a c Z^{\mathbf{b}}$ & Competed out by Mtx \\
\hline $\operatorname{MTK}(1 \times)$ & 5-Methylthioribose kinase & At1g49820 & Mtx-CAMe & Wounded leaves & $\mathrm{No}^{\mathrm{C}}$ & Yes \\
\hline SPL3 $(37 x)$ & Transcription factor & At2g33810 & Mtx-Cpd8 & Inflorescence & $n d^{e}$ & Yes \\
\hline
\end{tabular}

Candidate targets were identified by screening for yeast growth on selective medium (-Leu) supplemented with the bait indicated. A total of about $10^{6}$ colonies were screened for each library and bait. No candidates were obtained with Mtx-JA, Mtx-CA, and Mtx-ABA.

${ }^{a}$ The number of hits in brackets shown for each target represents the total number of independent yeast colonies identified during the cDNA library screenings. ${ }^{b} \mathrm{All}$ initial candidates were validated by retransfection into new yeast cells, activation of the second reporter gene (lacZ), and competition between the bait and Mtx. 'See Figure 4B.

${ }^{\top}$ The corresponding CDNA is not full length, the protein is truncated at the N-terminus.

e Not determined. 
2011). Fatty acid epoxides are precursors of jasmonate and other oxylipins and $\mathrm{EH}$ may play yet unknown roles in generation of signals for activation of certain defense responses (Mosblech et al., 2009; Wasternack and Kombrink, 2010). However, the Arabidopsis $\mathrm{EH}$ identified here has not been studied previously and therefore its function remains unknown. MTK is a key enzyme of the methionine cycle, which is essential for sulfur metabolism and ethylene biosynthesis (Sauter et al., 2004; Bürstenbinder et al., 2007). Regulation of this enzymatic step by jasmonates may be involved in coordinated biosynthesis of ethylene and jasmonate, which are known to function cooperatively (Lorenzo and Solano, 2005; Wasternack, 2007; Pieterse et al., 2009). Likewise it is tempting to speculate that SA-mediated activation of defense responses not only occurs via protein kinases (Brodersen et al., 2006; Bartels et al., 2009), but may also involve protein phosphatases, such as PP2C6 acting on unknown substrates. PP2C6 shares high sequence similarity with other members of the protein phosphatase family (up to $87 \%$ ), but whether or not this results in functional redundancy has not yet been explored (Schweighofer et al., 2004). The SBP-domain containing proteins are a group of plant-specific transcription factors that are encoded by moderately sized gene families in all seed plants, and in Arabidopsis it is represented by 17 members of the SPL gene family (Cardon et al., 1999; Riese et al., 2007). Individual family members are known to be involved in developmental programs, e.g., floral transition and leaf serration, as well as stress and hormone responses. However, redundancy resulting from the high degree of similarity between different family members seriously impairs functional analyses and therefore knowledge of the regulatory mechanism of SBP-box transcription factors is rather limited (Riese et al., 2007). It is tempting to speculate that Cpd8 may function as molecular glue, mimicking an unknown natural compound that helps to assemble an active transcriptional protein complex.

Obviously, our $\mathrm{Y} 3 \mathrm{H}$ approach did not yield any of the recently identified receptors of the plant hormones, ABA or JA (Chini et al., 2007; Thines et al., 2007; Ma et al., 2009; Park et al., 2009). Also, the targeted approach, expressing the ABA and JA receptors PYR1/RCAR1 and COI1, respectively, as fishes in yeast did not yield detectable interactions with the baits Mtx-ABA or MtxJA. In view of the resolved structures of both hormone receptors these results are not surprising because (1) both hormones bind at the interfaces of multimeric protein complexes, which cannot be resolved by the $\mathrm{Y} 3 \mathrm{H}$ approach; (2) ABA is completely embedded in its dimeric receptor (Lumba et al., 2010), and the Mtx-tagged hormone apparently does not allow formation of a stable complex with a single component; (3) the bioactive jasmonate is indeed the JA-Ile conjugate (Browse, 2009; Fonseca et al., 2009), which we have not yet used for bait synthesis; (4) both ABA and JA are hydrophobic small molecules that require very close interaction with putative receptors to afford tight binding, because their binding relies solely on weak Van der Waals forces (in contrast to strong electrostatic interactions between polar molecules such as JA-Ile). Nevertheless, we note that the $\mathrm{Y} 3 \mathrm{H}$ screening provided interesting and promising new hits as starting points for further studies, but the biological significance of the interactions between the candidate target proteins and the small molecule moieties of the corresponding baits needs critical evaluation. This is obviously relevant since none of the identified putative targets are known to interact with the different test compounds employed. Therefore, the interactions need to be confirmed in vitro and/or in planta by experimental approaches that include binding assays with the unmodified small molecule and characterization of Arabidopsis mutants that are defective in the respective candidate target gene.

\section{EVALUATION OF THE METHODOLOGY: PROS AND CONS OF THE Y3H SYSTEM}

We have demonstrated that the $\mathrm{Y} 3 \mathrm{H}$ technology is a valid approach to isolate binding protein candidates of small bioactive molecules from plant sources in extension of previous successful applications to yeast and mammalian systems, which were nurtured from drug research aiming at drug target identification (Licitra and Liu, 1996; Becker et al., 2004; Dirnberger et al., 2006; Chidley et al., 2011). The clear advantages of the $\mathrm{Y} 3 \mathrm{H}$ system over biochemical approaches for target identification are as follows: (1) The interaction between the ligand and its binding protein is monitored in vivo; (2) the technology relies on expression cloning and thereby allows facile and direct identification of the protein targets by sequencing, and therefore, (3) the method is independent of the amount of biological starting material and should yield results, provided that the protein targets are represented in the cDNA library used; (4) the method can uncover multiple targets in single screen, but only one at a time (see interaction of Cpd8 with SPL isoforms), thus redundancy of gene function is not a problem, unlike in genetic screens, and similarly, (5) identification of target proteins that would cause a lethal phenotype when absent is likewise no problem, unlike in classical genetic screens.

Of course, all experimental approaches also have their limitations. Quite unexpectedly, and in contrast to common experience with the $\mathrm{Y} 2 \mathrm{H}$ system, we uncovered only very few candidate targets for most of the hybrid ligands we used for screening, some even yielding none. This presumably reflects the strength of the protein-ligand interaction, since the largest and most hydrophobic molecules such as Cpd8 and Dex provided numerous candidates (Table 1) and strong reporter activation (Figure 4A), respectively. Correspondingly, the success of a screen will be affected by the nature of the bait. To generate hybrid ligands requires chemical synthesis, which may be difficult or unaffordable depending on the nature or availability of the small molecules of interest. It is important to realize that the $\mathrm{Y} 3 \mathrm{H}$ system also suffers from some inherent limitations: (1) The read-out of the system is reporter gene activation and therefore only soluble target proteins that translocate to the yeast nucleus can be identified, whereas proteins localizing to organelles or membranes escape detection. (2) Identification of multimeric target protein complexes is not possible since only single cDNAs are expressed in individual yeast cells. (3) Both the bait and the target protein are hybrid molecules and the introduced modifications may impair their efficient interaction or other structural/steric constraints may prevent formation of a stable complex. (4) As mentioned earlier, uptake of hybrid ligands needs consideration since yeast has efficient drug extrusion systems.

Some of these inherent limitations can be circumvent by modifications that have recently been introduced to the $\mathrm{Y} 3 \mathrm{H}$ system. For instance, using a modified split-ubiquitin system allows monitoring small molecule-protein interactions outside of the 
yeast nucleus (Dirnberger et al., 2006). The system employs fusion proteins of the $\mathrm{N}$ - and $\mathrm{C}$-terminal ubiquitin halves to generate the hook and the fishes and relies on the reconstitution of ubiquitin upon their interaction with the bait, which triggers degradation of the Ura3 reporter system allowing growth of yeast cells in the presence of the otherwise toxic compound, 5 -fluoroorotic acid (Johnsson and Varshavsky, 1994). Similarly, the Sos recruitment system, originally designed to detect protein-protein interactions (Aronheim et al., 1997; Aronheim, 2001), has also successfully been modified for selective monitoring of receptor-ligand interactions occurring at the plasma membrane. The system relies on the inability of the yeast strain $\mathrm{cdc} 25 \mathrm{H}$ to grow at restrictive temperature $\left(37^{\circ} \mathrm{C}\right)$ due to a mutation in the $\operatorname{cdc} 25$ gene encoding a guanyl nucleotide exchange factor, which actives Ras signaling pathway. This temperature-sensitive phenotype can be rescued by expression of the human Sos gene, but only when the protein is targeted to the plasma membrane via protein-protein interaction or formation a ternary complex comprising two fusion proteins and a corresponding bait (Aronheim, 1997; Broder et al., 1998). In fact, we could demonstrate that myristylated, membrane-anchored GR recruited the DHFR-hSos fusion protein to the membrane only in the presence of the bait Mtx-Dex and thereby initiated Ras-dependent growth of the temperature-sensitive yeast mutant strain $\mathrm{cdc} 25 \mathrm{H}$ at restrictive temperature. Both methods expand the experimental conditions for detecting small molecule interactions with target proteins by the $\mathrm{Y} 3 \mathrm{H}$ system. Other modifications and developments aimed at circumventing the low permeability of yeast for chemicals, for example by designing a mammalian threehybrid system by adaptation of a mammalian protein-protein interaction trap (MAPPIT) system (Eyckerman et al., 2001; Tavernier et al., 2002; Caligiuri et al., 2006), or by deleting three genes encoding broad-spectrum drug transporters from the yeast genome to increase uptake of chemicals (Chidley et al., 2011). An interesting recent variant of the $\mathrm{Y} 3 \mathrm{H}$ system is the SNAP-tagbased version, which permits to covalently anchor the bait, a hybrid ligand of $\mathrm{O}^{6}$-benzylguanine with a small molecule, to the hook, a fusion between the SNAP protein and the LexA DBD, and to screen for interacting target proteins by transcriptional activation of reporter genes as in the conventional $\mathrm{Y} 3 \mathrm{H}$ system (Chidley et al., 2011). This system not only stabilizes the hook-bait interaction, but it also allows independent validation of the binding of the small molecule to the target protein by affinity chromatography, using a

\section{REFERENCES}

Abida, W. M., Carter, B. T., Althoff, E. A., Lin, H., and Cornish, V. W. (2002). Receptor-dependence of the transcription read-out in a small-molecule threehybrid system. Chembiochem 3, 887-895.

Akiyama, K., Ogasawara, S., Ito, S., and Hayashi, H. (2010). Structural requirements of strigolactones for hyphal branching in AM fungi. Plant Cell Physiol. 51, 1104-1117.

Armstrong, J. I., Yuan, S., Dale, J. M., Tanner, V. N., and Theologis, A. (2004). Identification of inhibitors

matrix with immobilized GST-SNAP fusion protein and anchored small molecule. Such approach is very convenient because independent confirmation of $\mathrm{Y} 3 \mathrm{H}$ interactions outside of yeast cells is not always an easy task, as we were taught by own experience with candidate targets. Thus, despite obvious limitations, the $\mathrm{Y} 3 \mathrm{H}$ system has sufficient potential to generate candidates for subsequent in vivo and in planta analysis. In addition, further modifications of the technology can be envisioned to expand its application, for example by coupling Mtx to peptides, oligonucleotides, or other biomolecules.

\section{CONCLUSION}

The $\mathrm{Y} 3 \mathrm{H}$ system shows great promise as a tool for scanning whole expressed genomes for binding proteins of small molecules. It has been successfully used to identify and/or confirm mammalian targets of several inhibitors or drugs (Licitra and Liu, 1996; Henthorn et al., 2002; Becker et al., 2004; Dirnberger et al., 2006; Chidley et al., 2011). We have demonstrated that this direct functional cloning strategy can also be applied to plant systems and that several synthesized hybrid ligands comprising plant-specific small signaling molecules allowed the identification and isolation of putative protein targets from various plant cDNA libraries. Although the $\mathrm{Y} 3 \mathrm{H}$ system is still a relatively new technology (Licitra and Liu, 1996), it received several modifications with the aim to circumvent some of its inherent limitations, such as the requirement for nuclear targeting or high-affinity binding (Dirnberger et al., 2006; Chidley et al., 2011). Such refinements will expand the experimental conditions for application of $\mathrm{Y} 3 \mathrm{H}$ systems and it can be expected that many more protein targets of drugs and other small molecules will be identified with this innovative technology. However, the relative complexity of the system also requires a committed investment into the creation and optimization of its different modules such as chemical synthesis and molecular cloning and screening strategies.

\section{ACKNOWLEDGMENTS}

This work was funded by the DFG grant KO1192/9-1 within the framework of the Arabidopsis Functional Genomics Network (AFGN) and the Max Planck Society. Markus Kaiser acknowledges generous support by an ERC Starting Grant. We thank Dr. Virginia Cornish (Columbia University, New York, USA) for providing yeast strains and Mtx-Dex bait, Drs. Katja Schneider and Chiara Consonni for synthesis and sharing of cDNA libraries.

(1997). Isolation of an AP-1 repressor by a novel method for detecting protein-protein interactions. Mol. Cell. Biol. 17, 3094-3102.

Badri, D. V., Weir, T. L., van der Lelie, D., and Vivanco, J. M. (2009). Rhizosphere chemical dialogues: plantmicrobe interactions. Curr. Opin. Biotechnol. 20, 642-650.

Baker, K., Bleczinski, C., Lin, H., Salazar-Jimenez, G., Sengupta, D., Krane, S., and Cornish, V. W. (2002). Chemical complementation: a reaction-independent genetic assay for enzyme catalysis. Proc. Natl. Acad. Sci. U.S.A. 99, 16537-16542.
Baker, K., Sengupta, D., Salazar-Jimenez, G., and Cornish, V. W. (2003). An optimized dexamethasonemethotrexate yeast 3-hybrid system for high-throughput screening of small molecule-protein interactions. Anal. Biochem. 315, 134-137.

Bartels, S., Anderson, J. C., González Besteiro, M. A., Carreri, A., Hirt, H., Buchala, A., Métraux, J.-P., Peck, S. C., and Ulm, R. (2009). MAP kinase phosphatasel and protein tyrosine phosphatasel are repressors of salicylic acid synthesis and SNC1mediated responses in Arabidopsis. Plant Cell 21, 2884-2897. 
Becker, F., Murthi, K., Smith, C., Come, J., Costa-Roldán, N., Kaufmann, C., Hanke, U., Degenhart, C., Baumann, S., Wallner, W., Huber, A., Dedier, S., Dill, S., Kinsman, D., Hediger, M., Bockovich, N., Meier-Ewert, S., Kluge, A. F., and Kley, N. (2004). A three-hybrid approach to scanning the proteome for targets of small molecule kinase inhibitors. Chem. Biol. 11, 211-223.

Blackwell, H. E., and Zhao, Y. (2003). Chemical genetic approaches to plant biology. Plant Physiol. 133, 448-455.

Broder, Y. C., Katz, S., and Aronheim, A. (1998). The Ras recruitment system, a novel approach to the study of protein-protein interactions. Curr. Biol. 8, 1121-1130.

Brodersen, P., Petersen, M., Nielsen, H. B., Zhu, S., Newman, M.-A., Shokat, K. M., Rietz, S., Parker, J., and Mundy, J. (2006). Arabidopsis MAP kinase 4 regulates salicylic acid- and jasmonic acid/ethylenedependent responses via EDS1 and PAD4. Plant J. 47, 532-546.

Browse, J. (2009). Jasmonate passes muster: a receptor and targets for the defense hormone. Annu. Rev. Plant Biol. 60, 183-205.

Burdine, L., and Kodadek, T. (2004). Target identification in chemical genetics: the (often) missing link. Chem. Biol. 11, 593-597.

Bürstenbinder, K., Rzewuski, G., Wirtz, M., Hell, R., and Sauter, M. (2007). The role of methionine recycling for ethylene synthesis in Arabidopsis. Plant J. 49, 238-249.

Caligiuri, M., Molz, L., Liu, Q., Kaplan, F., Xu, J. P., Majeti, J. Z., RamosKelsey, R., Murthi, K., Lievens, S., Tavernier, J., and Kley, N. (2006). MASPIT: three-hybrid trap for quantitative proteome fingerprinting of small molecule-protein interactions in mammalian cells. Chem. Biol. 13, 711-722.

Campalans, A., Kondorosi, A., and Crespi, M. (2004). Enod40, a short open reading frame-containing mRNA, induces cytoplasmic localization of a nuclear RNA binding protein in Medicago truncatula. Plant Cell 16, 1047-1059.

Cardon, G., Höhmann, S., Klein, J., Nettesheim, K., Saedler, H., and Huijser, P. (1999). Molecular characterisation of the Arabidopsis SBP-box genes. Gene 237, 91-104.

Casida, J. E. (2009). Pest toxicology: the primary mechanisms of pesticide action. Chem. Res. Toxicol. 22, 609-619.

Cayley, P. J., Dunn, S. M. J., and King, R. W. (1981). Kinetics of substrate, coenzyme, and inhibitor binding to Escherichia coli dihydrofolate reductase. Biochemistry 20, 874-879.

Chidley, C., Haruki, H., Pedersen, M. G., Muller, E., and Johnsson, K. (2011). A yeast-based screen reveals that sulfasalazine inhibits tetrahydrobiopterin biosynthesis. Nat. Chem. Biol. 7, 375-383.

Chini, A., Fonseca, S., Fernández, G. Adie, B., Chico, J. M., Lorenzo, O., García-Casado, G., López-Vidriero, I., Lozano, F. M., Ponce, M. R., Micol, J. L., and Solano, R. (2007). The JAZ family of repressors is the missing link in jasmonate signalling. Nature 448, 666-671.

Chow, B., and McCourt, P. (2006). Plant hormone receptors: perception is everything. Genes Dev. 20, 1998-2008.

Cock, J. M., Vanoosthuyse, V., and Gaude, T. (2002). Receptor kinase signalling in plants and animals: distinct molecular systems with mechanistic similarities. Curr. Opin. Cell Biol. 14, 230-236.

de Felipe, K. S., Carter, B. T., Althoff, E. A., and Cornish, V. W. (2004). Correlation between ligandreceptor affinity and the transcription readout in a yeast threehybrid system. Biochemistry 43, 10353-10363.

Deck, P., Pendzialek, D., Biel, M., Wagner, M., Popkirova, B., Ludolph, B., Kragol, G., Kuhlmann, J., Giannis, A., and Waldmann, H. (2005). Development and biological evaluation of acyl protein thioesterase 1 (APT1) inhibitors. Angew. Chem. Int. Ed. Engl. 44, 4975-4980.

Delaney, J., Clarke, E., Hughes, D., and Rice, M. (2006). Modern agrochemical research: a missed opportunity for drug discovery? Drug Discov. Today 11, 839-845.

Depuydt, S., and Hardtke, C. S. (2011). Hormone signalling crosstalk in plant growth regulation. Curr. Biol. 21, R365-R373.

Dirnberger, D., Unsin, G., Schlenker, S., and Reichel, C. (2006). A smallmolecule-protein interaction system with split-ubiquitin as sensor. Chembiochem 7, 936-942.

Ercolin, F., and Reinhardt, D. (2011). Successful joint ventures of plants: arbuscular mycorrhiza and beyond. Trends Plant Sci. 16, 356-362.

Eyckerman, S., Verhee, A., der Heyden, J. V., Lemmens, I., Ostade, X. V., Vandekerckhove, J., and Tavernier, J. (2001). Design and application of a cytokine-receptor-based interaction trap. Nat. Cell Biol. 3, 1114-1119.

Fields, S., and Song, O. (1989). A novel genetic system to detect protein-protein interactions. Nature 340, 245-246

Fonseca, S., Chini, A., Hamberg, M., Adie, B., Porzel, A., Kramell, R., Miersch, O., Wasternack, C. and Solano, R. (2009). (+)-7iso-Jasmonoyl-L-isoleucine is the endogenous bioactive jasmonate. Nat. Chem. Biol. 5, 344-350.

Gallagher, S. S., Miller, L. W., and Cornish, V. W. (2007). An orthogonal dexamethasone-trimethoprim yeast three-hybrid system. Anal. Biochem. 363, 160-162.

Gangadhar, N. M., and Stockwell, B. R. (2007). Chemical genetic approaches to probing cell death. Curr. Opin. Chem. Biol. 11, 83-87.

Gbelska, Y., Krijger, J.-J., and Breunig, K. D. (2006). Evolution of gene families: the multidrug resistance transporter genes in five related yeast species. FEMS Yeast Res. 6, 345-355.

Gietz, R. D., and Woods, R. A (2002). Transformation of yeast by lithium acetate/single-stranded carrier DNA/polyethylene glycol method. Meth. Enzymol. 350, 87-96.

Gomi, K., Yamamato, H., and Akimitsu, K. (2003). Epoxide hydrolase: a mRNA induced by the fungal pathogen Alternaria alternata on rough lemon (Citrus jambhiri Lush). Plant Mol. Biol. 53, 189-199.

Grant, M. R., and Jones, J. D. G. (2009). Hormone (dis)harmony moulds plant health and disease. Science 324, 750-752.

Gulshan, K., and Moye-Rowley, W. S. (2007). Multidrug resistance in fungi. Eukaryot. Cell 6, 1933-1942.

Guo, A., Durner, J., and Klessig, D. F. (1998). Characterization of a tobacco epoxide hydrolase gene induced during the resistance response to TMV. Plant J. 15 647-656.

Henthorn, D. C., Jaxa-Chamiec, A. A. and Meldrum, E. (2002). A GAL4based yeast three-hybrid system for the identification of small moleculetarget protein interactions. Biochem. Pharmacol. 63, 1619-1628.

Hicks, G. R., and Raikhel, N. V. (2009). Opportunities and challenges in plant chemical biology. Nat. Chem. Biol. 5, 268-272.

Hwang, M. S., Kim, S. H., Lee, J. H. Bae, J. M., Paek, K. H., and Park, Y. I. (2005). Evidence for interaction between the 2 a polymerase protein and the 3 a movement protein of cucumber mosaic virus. J. Gen. Virol. 86, 3171-3177.

Jaeger, S., Eriani, G., and Martin, F (2004). Results and prospects of the yeast three-hybrid system. FEBS Lett. 556, 7-12.
Jaillais, Y., Belkhadir, Y., BalsemoãoPires, E., Dangl, J. L., and Chory, J. (2011). Extracellular leucine-rich repeats as a platform for receptor/coreceptor complex formation. Proc. Natl. Acad. Sci. U.S.A. 108, 8503-8507.

Johnsson, N., and Varshavsky, A. (1994). Split ubiquitin as a sensor of protein interactions in vivo. Proc. Natl. Acad. Sci. U.S.A. 91, 10340-10344.

Jones, K. M., Kobayashi, H., Davies, B. W., Taga, M. E., and Walker, G. C. (2007). How rhizobial symbionts invade plants: the SinorhizobiumMedicago model. Nat. Rev. Microbiol. 5, 619-633.

Kaiser, M., Wetzel, S., Kumar, K., and Waldmann, H. (2008). Biologyinspired synthesis of compound libraries. Cell. Mol. Life Sci. 65, 1186-1201.

Kaschani, F., Verhelst, S. H. L., van Swieten, P. F., Verdoes, M., Wong, C.-S., Wang, Z., Kaiser, M., Overkleeft, H. S., Bogyo, M., and van der Hoorn, R. A. L. (2009). Minitags for small molecules: detecting targets of reactive small molecules in living plant tissues using 'click chemistry'. Plant J. 57, 373-385.

Kawaguchi, M., and Minamisawa, K. (2010). Plant-microbe communications for symbiosis. Plant Cell Physiol. 51, 1377-1380.

Kim, T.-H., Hauser, F., Ha, T., Xue, S., Böhmer, M., Nishimura, N., Munemasa, S., Hubbard, K., Peine, N., Lee, B.-H., Lee, S., Robert, N., Parker, J. E., and Schroeder, J. I. (2011). Chemical genetics reveals negative regulation of abscisic acid signaling by a plant immune response pathway. Curr. Biol. 21, 990-997.

Kinghorn, A. D., Pan, L., Fletcher, J. N., and Chai, H. (2011). The relevance of higher plants in lead compound discovery programs. J. Nat. Prod. 74, 1539-1555.

Kley, N. (2004). Chemical dimerizers and three-hybrid systems: scanning the proteome for targets of organic small molecules. Chem. Biol. 11, 599-608.

Knoth, C., Salus, M. S., Girke, T., and Eulgem, T. (2009). The synthetic elicitor 3,5-dichloroanthranilic acid induces NPR1-dependent and NPR1-independent mechanisms of disease resistance in Arabidopsis. Plant Physiol. 150, 333-347.

Koehn, F. E., and Carter, G. T. (2005). The evolving role of natural products in drug discovery. Nat. Rev. Drug Discov. 4, 206-220.

Kolodziejek, I., Misas-Villamil, J. C., Kaschani, F., Clerc, J., Gu, C., Krahn, D., Niessen, S., Verdoes, M., Willems, 
L. I., Overkleeft, H. S., Kaiser, M., and van der Hoorn, R. A. L. (2011). Proteasome activity imaging and profiling characterizes bacterial effector syringolin A. Plant Physiol. 155, 477-489.

Koo, A. J. K., and Howe, G. A. (2009). The wound hormone jasmonate. Phytochemistry 70, 1571-1580.

Koornneef, A., and Pieterse, C. M. J. (2008). Cross talk in defense signaling. Plant Physiol. 146, 839-844.

Lemmon, M. A., and Schlessinger, J. (2010). Cell signaling by receptor tyrosine kinases. Cell 141, 1117-1134.

Li, C., Distelfeld, A., Comis, A., and Dubcovsky, J. (2011). Wheat flowering repressor VRN2 and promoter $\mathrm{CO} 2$ compete for interactions with NUCLEAR FACTOR-Y complexes. Plant J. 67, 763-773.

Li, J. (2011). Direct involvement of leucine-rich repeats in assembling ligand-triggered receptor-coreceptor complexes. Proc. Natl. Acad. Sci. U.S.A. 108, 8073-8074.

Li, L., Zhao, Y., McCaig, B. C., Wingerd, B. A., Wang, J., Whalon, M. E., Pichersky, E., and Howe, G. A. (2004). The tomato homolog of CORONATINE-INSENSITIVE1 is required for the maternal control of seed maturation, jasmonatesignaled defense responses, and glandular trichome development. Plant Cell 16, 126-143.

Licitra, E. J., and Liu, J. O. (1996). A three-hybrid system for detecting small ligand-protein receptor interactions. Proc. Natl. Acad. Sci. U.S.A. 93, 12817-12821.

Lin, H., Abida, W. M., Sauer, R. T., and Cornish, V. W. (2000). Dexamethasone-methotrexate: an efficient chemical inducer of protein dimerization in vivo. J. Am. Chem. Soc. 122, 4247-4248.

Lin, L.-C., Hsu, J.-H., and Wang, L.-C. (2010). Identification of novel inhibitors of 1-aminocyclopropane1-carboxylic acid synthase by chemical screening in Arabidopsis thaliana. J. Biol. Chem. 285, 33445-33456.

Lomenick, B., Hao, R., Jonai, N., Chin, R. M., Aghajan, M., Warburton, S., Wang, J., Wu, R. P., Gomez, F., Loo, J. A., Wohlschlegel, J. A., Vondriska, T. M., Pelletier, J., Herschman, H. R., Clardy, J., Clarke, C. F., and Huang, J. (2009). Target identification using drug affinity responsive target stability (DARTS). Proc. Natl. Acad. Sci. U.S.A. 106, 21984-21989.

Lorenzo, O., and Solano, R. (2005). Molecular players regulating the jasmonate signalling network. Curr. Opin. Plant Biol. 8, 532-540.

Lumba, S., Cutler, S., and McCourt, P. (2010). Plant nuclear hormone receptors: a role for small molecules in protein-protein interactions. Annu. Rev. Cell Dev. Biol. 26, 445-469.

Ma, Y., Szostkiewicz, I., Korte, A., Moes, D., Yang, Y., Christmann, A., and Grill, E. (2009). Regulators of PP2C phosphatase activity function as abscisic acid sensors. Science 324 , 1064-1068.

Maillet, F., Poinsot, V., Andre, O., Puech-Pages, V., Haouy, A., Gueunier, M., Cromer, L., Giraudet, D., Formey, D., Niebel, A., Martinez, E. A., Driguez, H., Becard, G., and Denarie, J. (2011). Fungal lipochitooligosaccharide symbiotic signals in arbuscular mycorrhiza. Nature 469, 58-63.

Maniataki, E., Martinez de Alba, E., Sägesser, R., Tabler, M., and Tsagris, M. (2003). Viroid RNA systemic spread may depend on the interaction of a 71-nucleotide bulged hairpin with the host protein VirP1. RNA 9, 346-354.

Mauch-Mani, B., and Mauch, F. (2005). The role of abscisic acid in plantpathogen interactions. Curr. Opin. Plant Biol. 8, 409-414.

Mayer, T. U. (2003). Chemical genetics: tailoring tools for cell biology. Trends Cell Biol. 13, 270-277.

McCourt, P., and Desveaux, D. (2010). Plant chemical genetics. New Phytol. 185, 15-26.

Möbius, N., and Hertweck, C. (2009). Fungal phytotoxins as mediators of virulence. Curr. Opin. Plant Biol. 12, 390-398.

Molinari, G. (2009). "Natural products in drug discovery: present status and perspectives," in Pharmaceutical Biotechnology, eds C. A. Guzman and G. Z. Feuerstein (Berlin: Springer-Verlag), 13-27.

Mosblech, A., Feussner, I., and Heilmann, I. (2009). Oxylipins: structurally diverse metabolites from fatty acid oxidation. Plant Physiol. Biochem. 47, 511-517.

Moye-Rowley, W. S. (2003). Transcriptional control of multidrug resistance in the yeast Saccharomyces. Prog. Nucleic Acid Res. Mol. Biol. 73, 251-279.

Murase, K., Hirano, Y., Sun, T.-P., and Hakoshima, T. (2008). Gibberellininduced DELLA recognition by the gibberellin receptor GID1. Nature 456, 459-463.

Murashige, T., and Skoog, F. (1962). A revised medium for rapid growth and bioassays with tobacco tissue cultures. Physiol. Plant. 15, 473-497.

Nagy, A., Szoke, B., and Schally, A. V. (1993). Selective coupling of methotrexate to peptide hormone carriers through a $\gamma$ carboxamide linkage of its glutamic acid moiety: benzotriazol-1yloxytris(dimethylamino)phospho nium hexafluorophosphate activation in salt coupling. Proc. Natl. Acad. Sci. U.S.A. 90, 6373-6376.

Nickel, S., Kaschani, F., Colby, T., van der Hoorn, R. A. L., and Kaiser, M. (in press). A para-nitrophenol phosphonate probe labels distinct serine hydrolases of Arabidopsis. Bioorg. Med. Chem. doi: 10.1016/j.bmc. 2011.06.041.

Nusinow, D. A., Helfer, A., Hamilton, E. E., King, J. J., Imaizumi, T., Schultz, T. F., Farre, E. M., and Kay, S. A. (2011). The ELF4-ELF3-LUX complex links the circadian clock to diurnal control of hypocotyl growth. Nature 475, 398-402.

Park, S.-Y., Fung, P., Nishimura, N., Jensen, D. R., Fujii, H., Zhao, Y., Lumba, S., Santiago, J., Rodrigues, A., Chow, T.-F. F., Alfred, S. E. Bonetta, D., Finkelstein, R., Provart, N. J., Desveaux, D., Rodriguez, P. L., McCourt, P., Zhu, J.-K., Schroeder, J. I., Volkman, B. F., and Cutler S. R. (2009). Abscisic acid inhibits type $2 \mathrm{C}$ protein phosphatases via the PYR/PYL family of START proteins. Science 324, 1068-1071.

Parniske, M. (2008). Arbuscular mycorrhiza: the mother of plant root endosymbioses. Nat. Rev. Microbiol. 6, 763-775.

Phizicky, E., Bastiaens, P. I. H., Zhu, H., Snyder, M., and Fields, S. (2003). Protein analysis on a proteomic scale. Nature 422, 208-215.

Pieterse, C. M. J., Leon-Reyes, A., Van der Ent, S., and Van Wees, S. C. M. (2009). Networking by smallmolecule hormones in plant immunity. Nat. Chem. Biol. 5, 308-316.

Riese, M., Höhmann, S., Saedler, H., Münster, T., and Huijser, P. (2007). Comparative analysis of the SBP-box gene families in $P$. patens and seed plants. Gene 401, 28-37.

Rietz, S., Stamm, A., Malonek, S., Wagner, S., Becker, D., Medina-Escobar N., Vlot, A. C., Feys, B. J., Niefind, K., and Parker, J. E. (2011). Different roles of enhanced disease susceptibility1 (EDS1) bound to and dissociated from phytoalexin deficient 4 (PAD4) in Arabidopsis immunity. New Phytol. 191, 107-119.

Rix, U., and Superti-Furga, G. (2009). Target profiling of small molecules by chemical proteomics. Nat. Chem. Biol. 5, 616-624.
Robert, S., Raikhel, N. V., and Hicks, G. R. (2009). Powerful Partners: Arabidopsis and Chemical Genomics. Rockville, MD: American Society of Plant Biologists.

Santner, A., and Estelle, M. (2009). Recent advances and emerging trends in plant hormone signalling. Nature 459, 1071-1078.

Sauter, M., Cornell, K. A., Beszteri, S., and Rzewuski, G. (2004). Functional analysis of methylthioribose kinase genes in plants. Plant Physiol. 136, 4061-4071.

Schneider, K., Wang, Z. M., Kaiser, M., and Kombrink, E. (2008). On the molecular mechanism of hormone action: hunting the jasmonate target(s). Curr. Top. Phytochem. 9, 1-16.

Schreiber, S. L. (2000). Target-oriented and diversity-oriented organic synthesis in drug discovery. Science 287, 1964-1969.

Schreiber, S. L. (2003). The smallmolecule approach to biology: chemical genetics and diversityoriented organic synthesis make possible the systematic exploration of biology. Chem. Eng. News 81, 51-61.

Schulze, B., Mentzel, T., Jehle, A. K. Mueller, K., Beeler, S., Boller, T., Felix, G., and Chinchilla, D. (2010). Rapid heteromerization and phosphorylation of ligand-activated plant transmembrane receptors and their associated kinase BAK1. J. Biol. Chem. 285, 9444-9451.

Schweighofer, A., Hirt, H., and Meskiene, I. (2004). Plant PP2C phosphatases: emerging functions in stress signaling. Trends Plant Sci. 9, 236-243.

Serrano, M., Hubert, D. A., Dangl, J. L., Schulze-Lefert, P., and Kombrink, E. (2010). A chemical screen for suppressors of the avrRpm1-RPM1dependent hypersensitive cell death response in Arabidopsis thaliana. Planta 231, 1013-1023.

Serrano, M., Robatzek, S., Torres, M., Kombrink, E., Somssich, I E., Robinson, M., and SchulzeLefert, P. (2007). Chemical interference of pathogen-associated molecular pattern-triggered immune responses in Arabidopsis reveals a potential role for fatty-acid synthase type II complex-derived lipid signals. J. Biol. Chem. 282, 6803-6811.

Sheerin, D. J., Buchanan, J., Kirk, C., Harvey, D., Sun, X., Spagnuolo, J. Li, S., Liu, T., Woods, V. A., Foster, T., Jones, W. T., and Rakonjac, J. (2011). Inter- and intra-molecular interactions of Arabidopsis thaliana DELLA protein RGL1. Biochem. J. $435,629-639$. 
Shimada, A., Ueguchi-Tanaka, M., Nakatsu, T., Nakajima, M., Naoe, Y., Ohmiya, H., Kato, H., and Matsuoka, M. (2008). Structural basis for gibberellin recognition by its receptor GID1. Nature 456, 520-523.

Smukste, I., and Stockwell, B. R. (2005). Advances in chemical genetics. Annu. Rev. Genomics Hum. Genet. 6, 261-286.

Speth, E. B., Lee, Y. N., and He, S. Y. (2007). Pathogen virulence factors as molecular probes of basic plant cellular functions. Curr. Opin. Plant Biol. 10, 580-586.

Spoel, S. H., and Dong, X. (2008). Making sense of hormone crosstalk during plant immune responses. Cell Host Microbe 3, 348-351.

Stintzi, A., and Browse, J. (2000). The Arabidopsis male-sterile mutant, opr3, lacks the 12-oxophytodienoic acid reductase required for jasmonate synthesis. Proc. Natl. Acad. Sci. U.S.A. 97, 10625-10630.

Stockwell, B. R. (2000). Chemical genetics: ligand-based discovery of gene function. Nat. Rev. Genet. 1, 116-125.

Stockwell, B. R. (2004). Exploring biology with small organic molecules. Nature 432, 846-854.

Strange, R. N. (2007). Phytotoxins produced by microbial plant pathogens. Nat. Prod. Rep. 24, 127-144.

Tavernier, J., Eyckerman, S., Lemmens, I., Van der Heyden, J., Vandekerckhove, J., and Van Ostade, X. (2002). MAPPIT: a cytokine receptor-based two-hybrid method in mammalian cells1. Clin. Exp. Allergy 32, 1397-1404.

Terstappen, G. C., Schlüpen, C., Raggiaschi, R., and Gaviraghi, G. (2007). Target deconvolution strategies in drug discovery. Nat. Rev. Drug Discov. 6, 891-903.

Thines, B., Katsir, L., Melotto, M., Niu, Y., Mandaokar, A., Liu, G., Nomura, K., He, S. Y., Howe, G. A., and Browse, J. (2007). JAZ repressor proteins are targets of the SCFCOI1 complex during jasmonate signalling. Nature 448, 661-665.

Tóth, R., and van der Hoorn, R. A. L. (2010). Emerging principles in plant chemical genetics. Trends Plant Sci. $15,81-88$.

Vollmeister, E., Haag, C., Zarnack, K., Baumann, S., König, J., Mannhaupt, G., and Feldbrügge, M. (2009). Tandem $\mathrm{KH}$ domains of Khd4 recognize AUACCC and are essential for regulation of morphology as well as pathogenicity in Ustilago maydis. RNA 15, 2206-2218.

Vuorela, P., Leinonen, M., Saikku, P., Tammela, P., Rauha, J. P., Wennberg, T., and Vuorela, H. (2004). Natural products in the process of finding new drug candidates. Curr. Med. Chem. 11, 1375-1389.

Walsh, T. A. (2007). The emerging field of chemical genetics: potential applications for pesticide discovery. Pest Manag. Sci. 63, 1165-1171.

Wang, Z., Gu, C., Colby, T., Shindo, T., Balamurugan, R., Waldmann, H., Kaiser, M., and van der Hoorn, R. A. L. (2008). $\beta$-Lactone probes identify a papain-like peptide ligase in Arabidopsis thaliana. Nat. Chem. Biol. 4 557-563.

Wasternack, C. (2007). Jasmonates: an update on biosynthesis, signal transduction and action in plant stress response, growth and development. Ann. Bot. 100, 681-697.

Wasternack, C., and Kombrink, E. (2010). Jasmonates: structural requirements for lipid-derived signals active in plant stress responses and development. ACS Chem. Biol. 5, 63-77.

Wijekoon, C. P., Goodwin, P. H., and Hsiang, T. (2008). The involvement of two epoxide hydrolase genes, NbEH1.1 and NbEH1.2, of Nicotiana benthamiana in the interaction with Colletotrichum destructivum, Colletotrichum orbiculare or Pseudomonas syringae pv. tabaci. Funct. Plant Biol. 35, 1112-1122.

Wijekoon, C. P., Goodwin, P. H., Valliani, M., and Hsiang, T. (2011). The role of a putative peroxisomaltargeted epoxide hydrolase of Nicotiana benthamiana in interactions with Colletotrichum destructivum, $C$. orbiculare or Pseudomonas syringae pv. tabaci. Plant Sci. 181, 177-187.

Wilk, W., Zimmermann, T. J., Kaiser M., and Waldmann, H. (2009). Principles, implementation, and application of biology-oriented synthesis (BIOS). Biol. Chem. 391, 491-497.

Wurster, S. E., and Maher, L. J. (2010). Selections that optimize
RNA display in the yeast threehybrid system. RNA 16, 253-258.

Zheng, X. S., Chan, T.-F., and Zhou, H. H. (2004). Genetic and genomic approaches to identify and study the targets of bioactive small molecules. Chem. Biol. 11, 609-618.

Conflict of Interest Statement: The authors declare that the research was conducted in the absence of any commercial or financial relationships that could be construed as a potential conflict of interest.

Received: 15 September 2011; paper pending published: 10 October 2011; accepted: 07 December 2011; published online: 26 December 2011.

Citation: Cottier S, Mönig T, Wang Z, Svoboda J, Boland W, Kaiser $M$ and Kombrink E (2011) The yeast threehybrid system as an experimental platform to identify proteins interacting with small signaling molecules in plant cells: potential and limitations. Front. Plant Sci. 2:101. doi: 10.3389/fpls.2011.00101 This article was submitted to Frontiers in Plant Physiology, a specialty of Frontiers in Plant Science.

Copyright $\odot 2011$ Cottier, Mönig, Wang, Svoboda, Boland, Kaiser and Kombrink. This is an open-access article distributed under the terms of the Creative Commons Attribution Non Commercial License, which permits non-commercial use, distribution, and reproduction in other forums, provided the original authors and source are credited. 